\title{
Maple Syrup Urine Disease
}

\section{Complete Primary Structure of the $\mathrm{E}_{1} \beta$ Subunit of Human Branched Chain $\alpha$-Ketoacid Dehydrogenase Complex Deduced from the Nucleotide Sequence and a Gene Analysis of Patients with This Disease}

Yoshitaka Nobukuni," Hiroshi Mitsubuchi," Fumio Endo," Izumi Akaboshi," Junichiro Asaka," and Ichiro Matsuda*

*Department of Pediatrics, Kumamoto University Medical School, Honjo 1-1-1, Kumamoto 860, Japan;

and ${ }^{\ddagger}$ Shionogi Institute for Medical Science, Settsu, Osaka 566, Japan

\begin{abstract}
$A$ defect in the $E_{1} \beta$ subunit of the branched chain $\alpha$-ketoacid dehydrogenase (BCKDH) complex is one cause of maple syrup urine disease (MSUD). In an attempt to elucidate the molecular basis of MSUD, we isolated and characterized a $1.35 \mathrm{kbp}$ cDNA clone encoding the entire precursor of the $E_{1} \beta$ subunit of BCKDH complex from a human placental cDNA library. Nucleotide sequence analysis revealed that the isolated cDNA clone $(\lambda \mathbf{h B E}, \beta-1)$ contrined a 5'-untranslated sequence of four nucleotides, the translated sequence of 1,176 nucleotides and the $3^{\prime}$-untranslated sequence of 169 nucleotides. Comparison of the amino acid sequence predicted from the nucleotide sequence of the cDNA insert of the clone with the $\mathrm{NH}_{2}$-terminal amino acid sequence of the purified mature bovine BCKDH$E_{1} \beta$ subunit showed that the $C D N A$ insert encodes for a 342 amino acid subunit with a $M_{\mathrm{r}}=37,585$. The subunit is synthesized as the precursor with a leader sequence of $\mathbf{5 0}$ amino acids and is processed at the $\mathbf{N H}_{2}$ terminus. A search for protein homology revealed that the primary structure of human $B C K D H-E_{1} \beta$ was similar to the bovine $B C K D H-E_{1} \beta$ and to the $E_{1} \beta$ subunit of human pyruvate dehydrogenase complex, in all regions. The structures and functions of mammalian $\alpha$-ketoacid dehydrogenase complexes are apparently highly conserved. Genomic DNA from lymphoblastoid cell lines derived from normal and five MSUD patients, in whom $E_{1} \beta$ was not detected by immunoblot analysis, gave the same restriction maps on Southern blot analysis. The gene has at least $80 \mathrm{kbp}$. (J. Clin. Invest. 1990. 86:242-247.) Key words: maple syrup urine disease - branched chain $\alpha$-ketoacid dehydrogenase • complementary DNA • cloning • gene analysis
\end{abstract}

\section{Introduction}

Mammalian branched chain $\alpha$-ketoacid dehydrogenase $(\mathrm{BCKDH})^{1}(\mathrm{EC} 1,2,4,4)$ is a mitochondrial multienzyme complex catalyzing the oxidative decarboxylation of branched

Address reprint requests to Ichiro Matsuda, M.D., Department of Pediatrics, Kumamoto University Medical School, Honjo 1-1-1, Kumamoto 860 , Japan.

Received for publication 11 January 1990 and in revised form 14 March 1990.

1. Abbreviations used in this paper: $\mathrm{BCKDH}$, branched chain $\alpha$-ketoacid dehydrogenase; MSUD, maple syrup urine disease; PDH, pyruvate dehydrogenase.

J. Clin. Invest.

(c) The American Society for Clinical Investigation, Inc.

0021-9738/90/07/0242/06 \$2.00

Volume 86, July 1990, 242-247 chain $\alpha$-ketoacids derived from amino acids such as valine, leucine, and isoleucine (reaction [1]).

$$
\begin{aligned}
& \mathrm{R}-\mathrm{COCOOH}+\mathrm{CoA}-\mathrm{SH}+\mathrm{NAD}^{+} \stackrel{\mathrm{TPP}, \mathrm{Mg}^{2+}}{\longrightarrow} \\
& \mathrm{R}-\mathrm{CO} \sim \mathrm{S}-\mathrm{COA}+\mathrm{CO}_{2}+\mathrm{NADH}+\mathrm{H}^{+}
\end{aligned}
$$

The BCKDH complex consists of three catalytic components: branched chain $\alpha$-ketoacid decarboxylase $\left(\mathrm{E}_{1}\right)$, dihydrolipoyl transacylase $\left(\mathrm{E}_{2}\right)$, and dihydrolipoamide dehydrogenase $\left(E_{3}\right) . E_{1}$ is further composed of two subunits, $E_{1} \alpha$ and $E_{1} \beta$ (1-3). $E_{1}$ and $E_{2}$ components are specific to $B C K D H$. On the other hand, the $\mathrm{E}_{3}$ component is common among the three ketoacid dehydrogenase complexes, $\mathrm{BCKDH}$, pyruvate dehydrogenase (PDH), and $\alpha$-ketoglutarate dehydrogenase $(4,5)$. The BCKDH complex also contains two specific regulatory enzymes, a kinase $(6-8)$ and a phosphatase $(9,10)$, responsible for regulation of the catalytic activity through phosphorylation and dephosphorylation.

$E_{1} \alpha$ is the catalytic subunit phosphorylated at two serine residues responsible for regulation of the catalytic activity by covalent modification (11-13). The function of $E_{1} \beta$ is unknown (5). $E_{2}$ catalyzes the transfer of the acyl group from the lipoyl moiety to coenzyme $A$ and forms the structural core of the enzyme complex. To this $E_{1}, E_{3}$, kinase, and phosphatase are bound through noncovalent interactions $(1,10,14)$.

Lack of BCKDH activity leads to maple syrup urine disease (MSUD), an autosomal recessive inborn error of metabolism (4). Several different phenotypes of MSUD have been elucidated on the basis of clinical features, as follows: classical, intermittent, intermediate, thiamine responsive type, $\mathrm{E}_{1} \beta$ deficiency, $E_{2}$ deficiency, and $E_{3}$ deficiency (4). Etiology of MSUD is heterogenous, as mutations in different regions of any of the BCKDH proteins could lead to decreased functions of the entire complex.

We reported that a defect in the $B C K D H-E_{1} \beta$ subunit is one cause of MSUD $(15,16)$. The isolation and characterization of cDNAs encoding all or a part of the human BCKDH$\mathrm{E}_{1} \alpha(17,18), \mathrm{BCKDH}-\mathrm{E}_{2}$ component (19-22), and $\mathrm{E}_{3}$ component $(23,24)$ have been reported but the primary structure of human BCKDH- $E_{1} \beta$ has not and the function of this subunit is not well understood. Molecular cloning of $B C K D H-E_{1} \beta$ had not been successful, despite repeated attempts. Most recently, we isolated a cDNA clone corresponding to bovine $\mathrm{BCKDH}-$ $E_{1} \beta$ (25). In an attempt to elucidate the molecular basis of the disease, we carried out cDNA cloning of the human BCKDH$E_{1} \beta$. The nucleotide sequence and the primary structure of human $\mathrm{BCKDH}-\mathrm{E}_{1} \beta$ has to be determined to analyze the alterations seen in studies on MSUD patients. We report herein isolation and characterization of a $1.35-\mathrm{kbp}$ cDNA clone that encodes the complete human $\mathrm{BCKDH}-\mathrm{E}_{1} \beta$ precursor. We also made a Southern blot analysis of the $B C K D H-E_{1} \beta$ gene in 
Epstein-Barr virus transformed lymphoblastoid cell lines derived from five nonrelated MSUD patients. BCKDH- $\mathrm{E}_{1} \beta$ was not detected by immunoblot analysis.

\section{Methods}

Materials. Restriction enzymes, pUC18 vector DNAs, 7-DEAZA Sequencing Kits, and random primer labeling kits were purchased from Takara Shuzo Co. (Kyoto, Japan). Nitrocellulose hybridization membranes were from Schleicher \& Schuell, Inc. (Kassel, Federal Republic of Germany). [ $\left.\alpha{ }^{32} \mathrm{P}\right] \mathrm{dCTP}$ (specific activity, 3,000 Ci/mmol) were from Amersham Corp. (Arlington Heights, IL).

Isolation of $c D N A$. The human placental cDNA library constructed in $\lambda$ gt 11 (26) was kindly provided by Dr. J. E. Sadler (Howard Hughes Medical Institute, Washington University School of Medicine). The 1.7-kbp cDNA clone $\left(\lambda b E_{1} \beta-2\right)$ for bovine $B C K D H-E_{1} \beta$ was isolated using the mixture of synthetic oligonucleotides ( $17 \mathrm{mer}, 24$ mixture) as a probe for a bovine liver cDNA library constructed in $\lambda \mathrm{gt} 11$ (25). Approximately $6 \times 10^{5}$ recombinant phage plaques were screened from the human placental cDNA library using the 1.7-kbp cDNA clone $\left(\lambda b E_{1} \beta-2\right)$ as a probe. The insert was labeled with $\left[\alpha-{ }^{32} \mathrm{P}\right] \mathrm{dCTP}$ $(3,000 \mathrm{Ci} / \mathrm{mmol})$ using the random primer labeling kit. Prehybridization, hybridization, and washing of nitrocellulose filters were as described (27). Hybridizing plaques detected by autoradiography were picked up from the mother agar plate. Successive screenings were carried out, using fewer and fewer plaques at each step until well-isolated phage plaques had been cloned.

Restriction endonuclease map and nucleotide sequence analysis. Recombinant phage DNA was prepared as described (28). Eco RI-excised cDNA inserts were subcloned into plasmid vector pUC18 and characterized by restriction endonuclease mapping. Restriction fragments were subcloned into pUC18 for sequencing. In addition, ordered serial deletions from the $5^{\prime} \rightarrow 3^{\prime}$ end of both strands of the pUC1 8 insert were produced with exonuclease III/mung bean nuclease for sequencing (29). DNA sequencing was performed by the dideoxy chain termination method (30) using an alkali-denatured plasmid as the template (31).

Protein data base search. Homologous amino acid sequences were sought in the GenBank (Release 59.0)/EMBL (Release 18.0) protein data base on a VAX computor using the Wordsearch program (32) (Version 6.0, April 1989). The Segments program was used for the alignment procedure.

Cell lines and cell culture. Lymphoblastoid cell lines derived from disease-free control male, and MSUD patients were established by Epstein-Barr virus-infected transformation of peripheral blood B lymphocytes (33). Kinetic studies on BCKDH activities and immunoblot analysis of BCKDH proteins of these cell lines from MSUD patients (K.Y., Y.T., E.K., T.Ho., Y.O.) have been reported (16). Lymphoblastoid cells were grown in RPMI 1640 medium containing penicillin $(100 \mathrm{IU} / \mathrm{ml})$ and streptomycin $(100 \mu \mathrm{g} / \mathrm{ml})$ supplemented with $10 \%$ FCS in an incubator at $37^{\circ} \mathrm{C}$. A subculture and a harvest were performed as described (15).

Southern blot analysis of genomic DNA. Total human genomic DNA was prepared from the lymphoblastoid cell lines, as described (34). Southern blotting was performed with 5.0-7.5 $\mu \mathrm{g}$ of total genomic DNA. DNA was cut by restriction enzymes Bam HI, Eco RI, and Hind III, and subjected to electrophoresis on an $0.8 \%$ agarose gel for 14-20 h at $40 \mathrm{~V}$. Southern blot hybridization was principally carried out according to the description of Southern (35). The cDNA insert $\left(\lambda \mathrm{hBE}_{1} \beta-1\right)$ was radiolabeled using a random primer labeling kit and $\left[\alpha-{ }^{32} \mathrm{P}\right] \mathrm{dCTP}(3,000 \mathrm{Ci} / \mathrm{mmol})$. The filters were prehybridized for $3 \mathrm{~h}$ in $50 \%$ Formamide, $5 \times \mathrm{SSC}, 100 \mu \mathrm{g} / \mathrm{ml}$ salmon testis DNA, $50 \mathrm{mM}$ sodium phosphate ( $\mathrm{pH} 6.5$ ), $0.1 \% \mathrm{SDS}$, and $10 \times$ Denhardt's solution $(1 \times$ Denhardt's $=0.02 \%$ polyvinylpyrrolidone, $0.02 \% \mathrm{BSA}, 0.02 \%$ Ficoll). Hybridization was for $24 \mathrm{~h}$ in prehybridization buffer containing the labeled cDNA insert. The filters were washed for $1 \mathrm{~h}$ at $56^{\circ} \mathrm{C}$ in $0.1 \times$ SSC and $0.1 \%$ SDS with two to three changes. Nitrocellulose membrane filters were exposed to film with intensifying screens at $-76^{\circ} \mathrm{C}$ for $3-5 \mathrm{~d}$.

\section{Results and Discussion}

To isolate the human BCKDH- $\mathrm{E}_{1} \beta$ cDNA clone, we initially screened $\sim 1 \times 10^{6}$ recombinant phage plaques of a human placental cDNA library constructed in $\lambda g t 11$ (26), with a specific rabbit antibody raised against bovine $B C K D H-E_{1} \beta$, and obtained five positive clones. All were found to be false positive by nucleotide sequencing.

We then isolated and characterized a cDNA clone coding for bovine $\mathrm{BCKDH}-\mathrm{E}_{1} \beta$ from a bovine liver cDNA library constructed in $\lambda \mathrm{gt} 11$ by screening with a mixture of synthetic oligonucleotide probes corresponding to the $\mathrm{COOH}$-terminal 5 -residue sequence of the bovine $\mathrm{BCKDH}-\mathrm{E}_{1} \beta(25)$. Using this 1.7-kbp Eco RI fragment of bovine BCKDH- $\mathrm{E}_{1} \beta$ cDNA insert $\left(\lambda b E_{1} \beta-2\right)$ as a probe, $\sim 6 \times 10^{5}$ plaque-forming units were screened from a human placental cDNA library. Only one positive clone $\left(\lambda \mathrm{hBE}_{1} \beta-1\right)$ was plaque purified to homogeneity through five successive rounds of screening, and the cDNA inserts were subcloned into the Eco RI site of pUC18 for further characterization. This recombinant phage clone insert had $1.35 \mathrm{kbp}$

The restriction endonuclease map of a cDNA insert from the phage clone $\lambda \mathrm{hBE}_{1} \beta-1$ and sequencing strategy for the insert are shown in Fig. 1. The nucleotide sequence and deduced amino acid sequence are shown in Fig. 2 . The $\lambda \mathrm{hBE}_{1} \beta-1$ insert is composed of $1,349 \mathrm{bp}$ consisting of a 4-bp 5'-untranslated sequence, a 1,176-bp-long open reading frame, and a 169-bp 3 '-untranslated sequence. The nucleotide sequence surrounding the putative initiator codon, GGGGAUGG, is rather different from the consensus sequence of CC ${ }_{G}^{A} C C A U G G$ (36). A polyadenylation signal of the type AATAAT (37) is found $7 \mathrm{bp}$ upstream of a poly (A) tail.

The open reading frame could be translated into a $392-$ amino acid residue protein. Comparison of the amino acid sequence predicted from the nucleotide sequence of the clone cDNA insert with the $\mathrm{NH}_{2}$-terminal amino acid sequence of purified bovine $\mathrm{BCKDH}-\mathrm{E}_{1} \beta$ determined by Edman degradation (25) revealed that the $\mathrm{NH}_{2}$-terminal 50-amino acid residues of the putative precursor protein are missing the mature $\mathrm{E}_{1} \beta . \mathrm{BCKDH}-\mathrm{E}_{1} \beta$ is a nuclear encoded mitochondrial protein, the precursor of which seems to contain a leader sequence of 50 amino acid residues. Comparison of the putative $E_{1} \beta$ leader sequence (negatively numbered amino acid residues in Fig. 2) with those of other mitochondrial proteins revealed a number of common features. The putative $\mathrm{E}_{1} \beta$ leader sequence con-

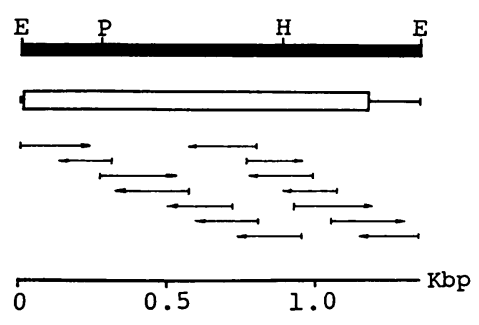

Figure 1. Restriction map and sequencing strategy for human BCKDH-E $\beta$ cDNA. The open box and the line depict coding and noncoding regions, respectively. Restriction sites are indicated above the $\lambda \mathrm{hBE}_{1} \beta-1$ insert $(1,349 \mathrm{bp})$ at the top of the figure,

with restriction enzymes used: Eco RI $(E)$, Pst I $(P)$, Hind III $(H)$. Solid horizontal arrows indicate orientation and region of sequencing. 
ATGGCGGTTGT AGCGGCGGCTGCCGGCTGGCTACTCAGGCTCAGGGCGGCAGGGGCTGAGGGGCACTGGCGTCGGCTTCCTGGCGCGGGG

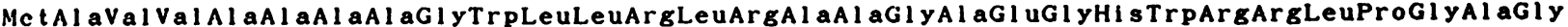
$-50$ $-40$ $-30$

CTGGCGCGGGGCTTTTTGCACCCCGCCGCGACTGTCGAGGATGCGGCCCAGAGGCGGCAGGTGGCTCATTTTACTTTCCAGCCAGATCCG LeuAl aArgGl yPheLeuHi s ProAl aAl aThrValGl uAs PAl aAl aGl nArgArgGl nVal Al aHis PheThrPheGl nProAspPro $-20$ $-10$ 1

GAGCCCCGGGAGTACGGGCAAACTCAGAAAATGAATCTTTTCCAGTCTGTAACAAGTGCCTTGGATAACTCATTGGCCAAAGATCCT ACT GI UProArgGI UTyrGI YGI nThrGI nLysMetAsnLeuPheGI nSerVal ThrSerAl aLeuAspAsnSerLeuAl aLysAspProThr 20 30

GCAGTAATATTTGGTGAAGATGTTGCCTTTGGTGGAGTCTTTAGATGCACTGTTGGCTTGCGAGACAAATATGGAAAAGATAGAGTTTTT AlaVal I ePheGl yGl uAspVal AlaPheGl yGl yVal PheArgCysThrValGl yLeuArgAspLystyrgl yLysAspargVal Phe

AATACCCCATTGTGTGAACAAGGAATTGTTGGATTTGGAATCGGAATTGCGGTCACTGGAGCTACTGCCATTGCGGAAATTCAGTTTGCA

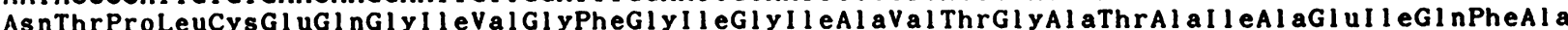
80 90

GATTATATTTTCCCTGCATTTGATCAGATTGTTAATGAAGCTGCCAAGTATCGCTATCGCTCTGGGGATCTTTTTAACTGTGGAAGCCTC AspTyrI l ePheProAl aPheAspGInI leVal AsnGluAl aAl aLys TyrArgTyrArgSerGl yAspLeuPheAsnCysGl ySerLeu 110 120

ACTATCCGGTCCCCTTGGGGCTGTGTTGGTCATGGGGCTCTCTATCATTCTCAGAGTCCTGAAGCATTTTTTGCCCATTGCCCAGGAATC ThrIl eArgSerProTrPGI yCysValGl yHISGI yAl aLeuTyrHisSerGinSerProGluAlaPhePheAlaHisCysProGl yI Ie 140 150

AAGGTGGTTATACCCAGAAGCCCTTTCCAGGCCAAAGGACTTCTTTTGTCATGCATAGAGGATAAAAATCCTTGTATATTTTTTGAACCT Lys 17001800

AAAAT ACTTT ACAGGGCAGCAGCGGAAGAAGTCCCTAT AGAACCATACAACATCCCACTGTCCCAGGCCGAAGTCATACAGGAAGGGAGT

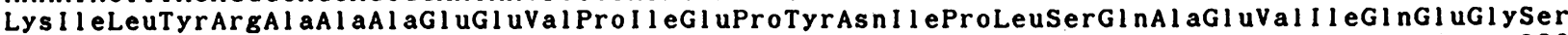
200

210

GATGTTACTCTAGTTGCCTGGGGCACTCAGGTTCATGTGATCCGAGAGGT AGCTTCCATGGCAAAAGAAAAGCTTGGAGTGTCTTGTGAA AspVal ThrLeuVal Al aTrPGI yThrGI nValHisVal I l eArgGl uVal Al aSerMe tAl aLysGluLysLeuGIyValSerCysGIu 230 240

GTCATTGATCTGAGGACTATAATACCTTGGGATGTGGACACAATTTGTAAGTCTGTGATCAAAACAGGGCGACTGCTAATCAGTCACGAC

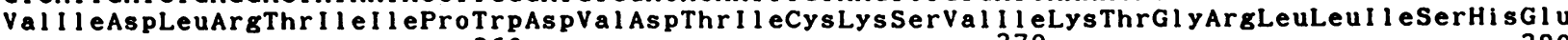
260 270

GCTCCCTTGACAGGCGGCTTTGCATCGGAAATCAGCTCTACAGTTCAGGAGGAATGTTTCTTGAACCTAGAGGCTCCTATATCAAGAGTA

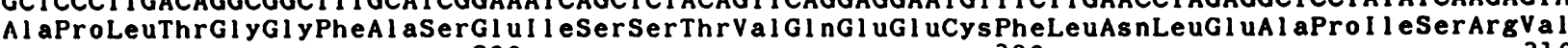
290 300

TGTGGTTATGACACACCATTTCCTCACATTTTTGAACCATTCTACATCCCAGACAAATGGAAGTGTTATGATGCCCTTCGAAAAATGATC CysGI yTyrAspThrProPheProHis I l ePheGI uProPheTyrI 1 eProAspLysTrpLysCysTyrAspAl aLeuArgLysMet I le 320 330 AsnTyr***

TCAGTGTTTTGATGGTAACAAACTTTGATGGTAAAGTTGATAAAAGGCAACTTTCAGAAGAAAATAATGTGCTTT AAAAAAAAAA

Figure 2. Nucleotide sequence of the $\lambda \mathrm{hBE}_{1} \beta-1$ insert and deduced amino acid sequence of the human $\mathrm{BCKDH}-\mathrm{E}_{1} \beta$ precursor. Numbers on the far right correspond to ordinate of the last nucleotide in each row. Nucleotides are numbered in the $5^{\prime} \rightarrow 3^{\prime}$ direction, beginning with the first residue of the ATG triplet encoding the putative initiator methionine. Numbers below the amino acid sequence refer to residues beginning with the $\mathrm{NH}_{2}$ terminus of the mature protein deduced from the purified bovine BCKDH- $\mathrm{E}_{1} \beta$ determined by Edman degradation (25). There is a double underline at the polydenylation signal of the type AATAAT (37).

tains periodically spaced basic amino acids rich in Leu and Arg and has few acidic residues (only one Asp at residue -7). These findings are compatible with those proposed for the leader sequence of mitochondrial targetting enzymes $(38,39)$. On the basis of these findings, the molecular mass of the $E_{1} \beta$ precursor is estimated to be 43,130 and that of the mature $E_{1} \beta$ is 37,585 , in good agreement with the 37,000 estimated by immunoblot analysis $(15,16)$.
A protein homology search revealed that the primary structure of human $\mathrm{BCKDH}-\mathrm{E}_{1} \beta$ is similar to the human PDH-E $\beta$ (40), in all regions. Fig. 3 depicts the alignment of homologous regions of human $B C K D H-E_{1} \beta$, bovine BCKDH-E $\beta$, and human PDH- $E_{1} \beta .98 \%$ of the amino acid residues of human $B C K D H-E_{1} \beta$ are identical to bovine $B C K D H-E_{1} \beta$ and $33 \%$ of the amino acid residues of human $\mathrm{BCKDH}-\mathrm{E}_{1} \beta$ are identical to the corresponding residues of 


\begin{abstract}
Bovine BCKDH 1 VAHFTFQPDPEPVEYGQTQKMNLFQAVTSALDINSAKDPTAVIFGEDVA-FGGVFRCTVG 59 Human BCKDH 1 VAHFTFQPDPEPREYGQTQKMNLFQS VTSALDNSLAKDPTAVIFGEDVA-FGGVFRCTVG 59 Human PDH $24-$ - HW

Bovine BCKDH 60 LRDKYGKDRVFNTPLCEQGIVGFGIGIAVTGATAIAEIQFADYIFPAFDQIVNEAAKYRY 119 Human BCKDH 60 LRDKYGKDRVFNTPLCEQGIVGFGIGIAVTGATAIAEIQFADYIFPAFDQIVNEAAKYRY II9 Human PDH 73 IWKKYGDKRIIDTP IEMGFAGIAVGARMAGLRPICEFMTFNFSMQATDQVINSAAKTYY 132
\end{abstract}

Bovine BCKDH 120 RSGDLFNCGSLTIRSPWGCVGHGALYHSQSPQAFFAHCPGIKVVVPRSPFQAKGLLLSCI 179 Human BCKDH 120 RSGDLFNCGSLTIRSPWGCVGHGALYHSQSPEAFFAHCPGIKVVVPRSPFQAKGLLLSCI 179

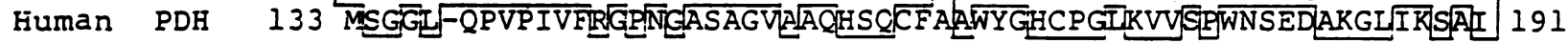

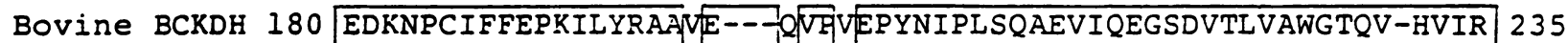
Human BCKDH 180 EDKNPCIFFEPKIIYRAAME---EVHIEPYNIPLSOAEVIQEGSDVTLVAWGTQV-HVIR 235

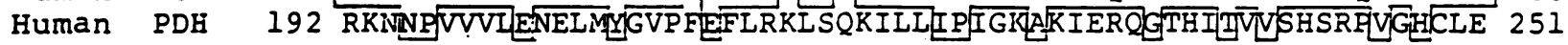

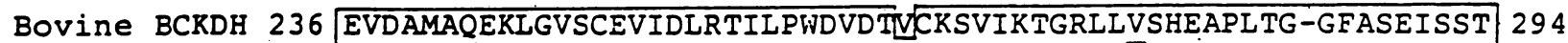
Human BCKDH 236 EVDAMAQEKLGVSCEVIDLRTIIPWDVDTICKSVIKTGRLIISHEAPLTG-GFASEISST 294 Human PDH 252 AAAVLSNE-GVECEVINMRTIRPMDMETIFASVMIT THE-LVIVEGGWPQFGVGAEICAR 308

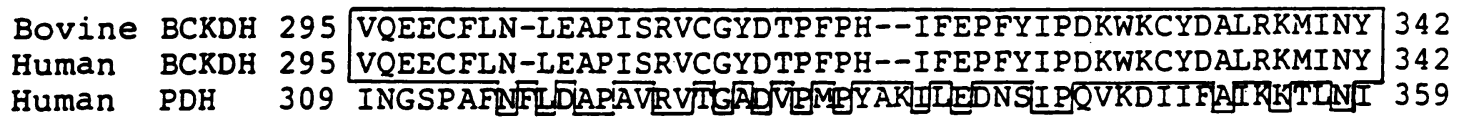

Figure 3. Comparison of amino acid sequences of human BCKDH- $\mathrm{E}_{1} \beta$ (present study), bovine BCKDH-E $\beta$ (25), and human PDH-E $\beta$ (40).

PDH-E $E_{1} \beta$; this similarity increased to $82 \%$ if conservative amino acid substitutions are taken into account. It has been demonstrated that mammalian $\alpha$-ketoacid dehydrogenase complexes such as PDH, BCKDH, and $\alpha$-ketoglutarate dehydrogenase are functionally and structurally similar $(4,5)$. The amino acid sequence of the mammalian $\mathrm{BCKDH}-\mathrm{E}_{1} \alpha$ is highly homologous to that of mammalian $\mathrm{PDH}_{-} \mathrm{E}_{1} \alpha$ (17); the same is true of $B C K D H-E_{2}(19-21)$. The present study showed that human $\mathrm{BCKDH}-\mathrm{E}_{1} \beta$ is also similarly homologous to human PDH- $\mathrm{E}_{1} \beta$. Extensive homologies between $\mathrm{BCKDH}-$
A

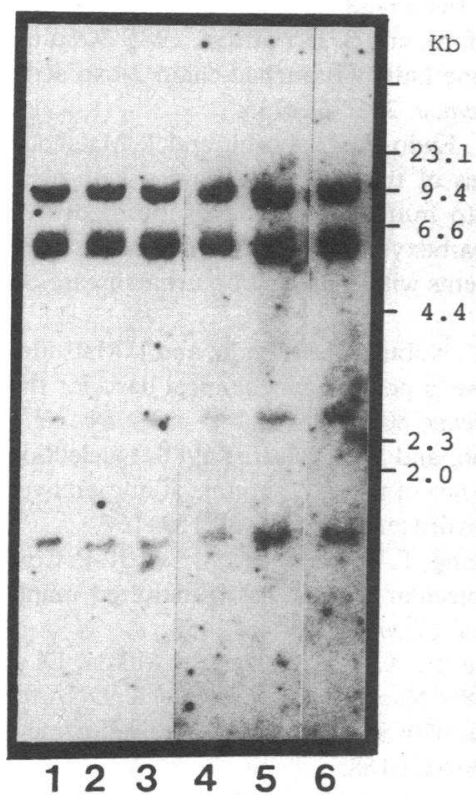

B

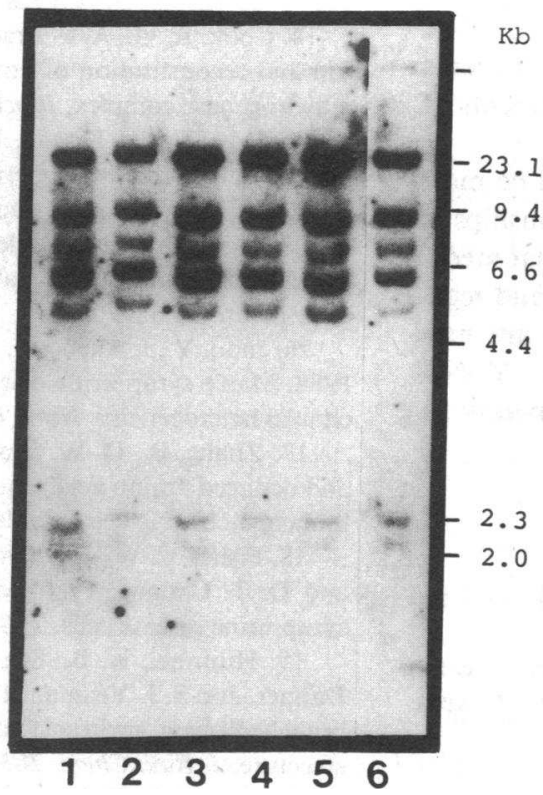

C

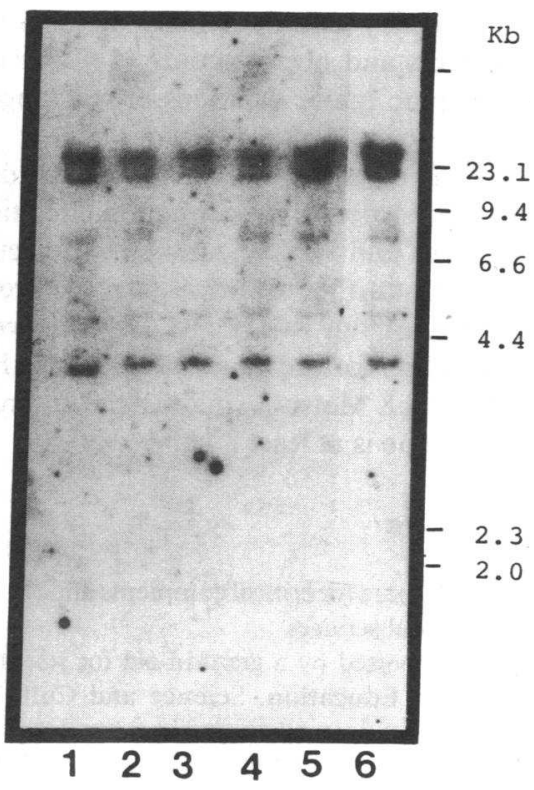

Figure 4. Southern blot analysis of genomic DNA from the MSUD patient in whom CRM for BCKDH-E $\beta$ are absent. $(A)$ Eco RI-digested genomic DNA. Lane 1, disease-free control cell line; lanes 2-6, cell lines from MSUD patients (K.Y., Y.T., E.K., T.Ho., and Y.O.). Filters were probed with labeled human BCKDH-E ${ }_{1} \beta$ cDNA $\left(\lambda \mathrm{hBE}_{1} \beta-1\right)$. $(B)$ Hind III-digested DNA from individuals as in $A$, hybridized with labeled human BCKDH-E $\beta_{1}$ cDNA $\left(\lambda \mathrm{hBE}_{1} \beta-1\right)$. (C) Bam HI-digested DNA from individuals as in $A$, hybridized with labeled human BCKDH-E $\beta$ cDNA $\left(\lambda \mathrm{hBE}_{1} \beta-1\right)$. The BCKDH-E $\beta$ gene is estimated to be at least $80 \mathrm{kbp}$ long as based on data obtained by cloning of the genomic DNA. 
$\mathrm{E}_{1} \beta$ and $\mathrm{PDH}-\mathrm{E}_{1} \beta$ throughout the primary structure suggest that the secondary structure, tertiary structure, and function are also similar. Furthermore $\mathrm{BCKDH}-\mathrm{E}_{1} \beta$ and $\mathrm{PDH}-\mathrm{E}_{1} \beta$ may possibly arise from a common ancestoral gene, although the function of $E_{1} \beta$ has yet to be determined (5). A highly conserved structure of the $E_{1} \beta$-subunit of 2-oxo acid dehydrogenases of mammals suggests that the $E_{1} \beta$-subunit of these enzymes no doubt plays important roles in enzyme activities.

A defect in the BCKDH complex results in MSUD (4). The etiology of this disease is heterogenous as mutations in different regions of any of the BCKDH proteins could lead to decreased functions of the entire complex. Recently, a defect of $E_{2}(15,16,18,41,42)$, a defect of $E_{1} \beta(15,16,18)$, mutation of $E_{1} \alpha$ (43), and loss of $E_{1} \alpha$ and $E_{1} \beta$ subunits (18) have been detected in MSUD patients.

We analyzed the biochemical basis for clinical heterogeneity in MSUD and noted a defect in $\mathrm{E}_{1} \beta$ as one cause of the disease. In these cases, immunologically cross-reactive material corresponding to $\mathrm{BCKDH}-\mathrm{E}_{1} \beta$ was not detected. $\mathrm{E}_{1} \beta$ is associated with $E_{1} \alpha$ by noncovalent binding and the $E_{1}$ subunit is attached to $E_{2}$. Thus, the absence of $E_{1} \beta$ theoretically could result from abnormalities in structures of $E_{1} \alpha$ or $E_{2}$. The absence of $E_{1} \beta$ might not indicate a genetic abnormality in the $E_{1} \beta$ gene. A detailed analysis of $E_{1} \beta$ deficiency suggested that the mutations might be heterogenous $(15,16)$. The $\mathrm{E}_{1} \beta$ deficiency will have to be analyzed at the gene level.

To elucidate the molecular mechanism of $\mathrm{E}_{1} \beta$ deficiency, we first analyzed the expression of $E_{1} \beta$ transcript in lymphoblastoid cell lines in which $\mathrm{E}_{1} \beta$ was not detected by immunoblot analysis $(15,16)$. The $\mathrm{E}_{1} \beta$ transcript was not clearly defined by Northern blot analysis using poly $(\mathrm{A})^{+}$RNA (10-15 $\mu \mathrm{g})$, even in normal control lymphoblastoid cell lines (data not shown). The quantity of the $\mathrm{E}_{1} \beta$ transcript may be low or the transcript may readily degrade, a proposal based on our finding that we could obtain only one clone when screening the cDNA-library using the nucleotide probe $\left(\lambda b E_{1} \beta-2\right)$, as described above.

We also analyzed by Southern blots the genomic DNA from MSUD patients and normal controls (Fig. 4). It seems likely that there are no major deletions or rearrangements of the $\mathrm{BCKDH}-\mathrm{E}_{1} \beta$ gene in these patients.

The cDNA clone of human BCKDH- $E_{1} \beta$ should be most useful for examining structural and functional relationships of the BCKDH complex and for elucidating the molecular mechanisms of MSUD. To further examine the structure and regulatory mechanisms of the $\mathrm{BCKDH}-\mathrm{E}_{1} \beta$ gene, we are now cloning genomic DNA for the gene (Mitsubuchi, H., Y. Nobukuni, F. Endo, and I. Matsuda, manuscript in preparation). The $\mathrm{BCKDH}-\mathrm{E}_{1} \beta$ gene is at least $80 \mathrm{kbp}$ long.

\section{Acknowledgments}

We are grateful to $M$. Ohara for critical comments and $M$. Hayashi and M. Tsutsui for secretarial services.

This work was supported by a grant-in-aid for scientific research from the Ministry of Education, Science and Culture of Japan (01480553).

\section{References}

1. Pettit, F. H., S. J. Yeaman, and L. J. Reed. 1978. Purification and characterization of branched chain $\alpha$-keto acid dehydrogenase complex of bovine kidney. Proc. Natl. Acad. Sci. USA. 75:4881-4885.

2. Danner, D. J., S. K. Lemmon, J. C. Besharse, and L. J. Elsas, II.
1979. Purification and characterization of branched chain $\alpha$-ketoacid dehydrogenase from bovine liver mitochondria. J. Biol. Chem. 254:5522-5526.

3. Heffelfinger, S. C., E. T. Sewell, and D. J. Danner. 1983. Identification of specific subunits of highly purified bovine liver branchedchain ketoacid dehydrogenase. Biochemistry. 22:5519-5522.

4. Danner, D. J., and L. J. Elsas, II. 1989. Disorders of branched chain amino acid and keto acid metabolism. In The Metabolic Basis of Inherited Disease. C. R. Scriver, A. L. Beaudet, W. S. Sly, and D. Valle, editors. McGraw-Hill Information Services Company, New York. 671-692.

5. Yeaman, S. J. 1989. The 2-oxo acid dehydrogenase complexes: recent advances. Biochem. J. 257:625-632.

6. Odessey, R. 1982. Purification of rat kidney branched-chain oxo acid dehydrogenase complex with endogenous kinase activity. Biochem. J. 204:353-356.

7. Lau, K. S., H. R. Fatania, and P. J. Randle. 1982. Regulation of the branched chain 2-oxoacid dehydrogenase kinase reaction. FEBS (Fed. Eur. Biochem. Soc.) Lett. 144:57-62.

8. Paxton, R., and R. A. Harris. 1982. Isolation of rabbit liver branched chain $\alpha$-ketoacid dehydrogenase and regulation by phosphorylation. J. Biol. Chem. 257:14433-14439.

9. Fatania, H. R., P. A. Patston, and P. J. Randle. 1983. Dephosphorylation and reactivation of phosphorylated purified ox-kidney branched-chain dehydrogenase complex by co-purified phosphatase. FEBS (Fed. Eur. Biochem. Soc.) Lett. 158:234-238.

10. Damuni, Z., M. L. Merryfield, J. S. Humphreys, and L. J. Reed. 1984. Purification and properties of branched-chain $\alpha$-keto acid dehydrogenase phosphatase from bovine kidney. Proc. Natl. Acad. Sci. USA. 81:4335-4338.

11. Cook, K. G., A. P. Bradford, S. J. Yeaman, A. Aitken, I. M Fearnley, and J. E. Walker. 1984. Regulation of bovine kidney branched-chain 2-oxoacid dehydrogenase complex by reversible phosphorylation. Eur. J. Biochem. 145:587-591.

12. Lau, K. S., C. E. Phillips, and P. J. Randle. 1983. Multi-site phosphorylation in ox-kidney branched-chain 2-oxoacid dehydrogenase complex. FEBS (Fed. Eur. Biochem. Soc.) Lett. 160:149-152.

13. Cook, K. G., R. Lawson, and S. J. Yeaman. 1983. Multi-site phosphorylation of branched-chain 2-oxoacid dehydrogenase complex within mitochondria isolated from rat liver, kidney and heart. FEBS (Fed. Eur. Biochem. Soc.) Lett. 164:85-88.

14. Cook, K. G., A. P. Bradford, and S. J. Yeaman. 1985. Resolution and reconstitution of bovine kidney branched-chain 2-oxo acid dehydrogenase complex. Biochem. J. 225:731-735.

15. Indo, Y., A. Kitano, F. Endo, I. Akaboshi, and I. Matsuda. 1987. Altered kinetic properties of the branched-chain $\alpha$-keto acid dehydrogenase complex due to mutation of the $\beta$-subunit of the branched-chain $\alpha$-keto acid decarboxylase $\left(\mathrm{E}_{1}\right)$ component in lymphoblastoid cells derived from patients with maple syrup urine disease. $J$. Clin. Invest. 80:63-70.

16. Indo, Y., I. Akaboshi, Y. Nobukuni, F. Endo, and I. Matsuda. 1988. Maple syrup urine disease: a possible biochemical basis for the clinical heterogeneity. Hum. Genet. 80:6-10.

17. Zhang, B., D. W. Crabb, and R. A. Harris. 1988. Nucleotide and deduced amino acid sequence of the $\mathrm{E} 1 \alpha$ subunit of human liver branched-chain $\alpha$-ketoacid dehydrogenase. Gene. 69:159-164.

18. Fisher, C. W., J. L. Chuang, T. A. Griffin, K. S. Lau, R. P. Cox, and D. T. Chuang. 1989. Molecular phenotypes in cultured maple syrup urine disease cells. J. Biol. Chem. 264:3448-3453.

19. Hummel, K. B., S. Litwer, A. P. Bradford, A. Aitken, D. J. Danner, and S. J. Yeaman. 1988. Nucleotide sequence of a cDNA for branched chain acyltransferase with analysis of the deduced protein structure. J. Biol. Chem. 263:6165-6168.

20. Lau, K. S., T. A. Griffin, C.-W. C. Hu, and D. T. Chuang. 1988 Conservation of primary structure in the lipoyl-bearing and dihydrolipoyl dehydrogenase binding domains of mammalian branched-chain $\alpha$-keto acid dehydrogenase complex: molecular cloning of human and bovine transacylase (E2) cDNAs. Biochemistry. 27:1972-1981.

21. Danner, D. J., S. Litwer, W. J. Herring, and J. Pruckler. 1989. 
Construction and nucleotide sequence of a cDNA encoding the fulllength preprotein for human branched chain acyltransferase. J. Biol. Chem. 264:7742-7746.

22. Nobukuni, Y., H. Mitsubuchi, F. Endo, and I. Matsuda. 1989. Complete primary structure of the transacylase (E2b) subunit of the human branched chain $\alpha$-keto acid dehydrogenase complex. Biochem. Biophys. Res. Commun. 161:1035-1041.

23. Otulakowski, G., and B. H. Robinson. 1987. Isolation and sequence determination of cDNA clones for porcine and human lipoamide dehydrogenase. J. Biol. Chem. 262:17313-17318.

24. Pons, G., C. Raefsky-Estrin, D. J. Carothers, R. A. Pepin, A. A Javed, B. W. Jesse, M. K. Ganapathi, D. Samols, and M. S. Patel. 1988. Cloning and cDNA sequence of the dihydrolipoamide dehydrogenase component of human $\alpha$-detoacid dehydrogease complexes. Proc. Natl. Acad. Sci. USA. 85:1422-1426.

25. Nobukuni, Y., H. Mitsubuchi, F. Endo, J. Asaka, R. Oyama, K. Titani, and I. Matsuda. 1990. Isolation and characterization of a complementary DNA clone coding for the $E_{1} \beta$ subunit of bovine branched-chain $\alpha$-ketoacid dehydrogenase complex: complete amino acid sequence of the precursor protein and its proteolytic processing. Biochemistry. 29:1154-1160.

26. Ye, R. D., T.-C. Wun, and J. E. Sadler. 1987. cDNA cloning and expression in Escherichia coli of a plasminogen activator inhibitor from human placenta. J. Biol. Chem. 262:3718-3725.

27. Maniatis, T., E. F. Fritsch, and J. Sambrook. 1982. Molecular Cloning: A Laboratory Manual. Cold Spring Harbor Laboratory, Cold Spring Harbor, NY. 312-328.

28. Maniatis, T., E. F. Fritsch, and J. Sambrook. 1982. Molecular Cloning: A Laboratory Manual. Cold Spring Harbor Laboratory, Cold Spring Harbor, NY. 371-372.

29. Henikoff, S. 1984. Unidirectional digestion with exonuclease III creates targeted breakpoints for DNA sequencing. Gene. 28:351359.

30. Sanger, F., S. Nicken, and A. R. Coulson. 1977. DNA sequencing with chain-terminating inhibitors. Proc. Natl. Acad. Sci. USA. 74:5463-5467.

31. Hattori, M., and Y. Sakaki. 1986. Dideoxy sequencing method using denatured plasmid templates. Anal. Biochem. 152:232-238.

32. Wilbur, W. J., and D. J. Lipman. 1983. Rapid similarity searches of nucleic acid and protein data banks. Proc. Natl. Acad. Sci. USA. 80:726-730.

33. Matsuda, I., J. Yamamoto, N. Nagata, N. Ninomiya, I. Akaboshi, H. Otsuka, and T. Katsuki. 1977. Lysosomal enzyme activities in cultured lymphoid cell lines. Clin. Chim. Acta. 80:483-486.

34. Kunkel, L. M., K. D. Smith, S. H. Boyer, D. S. Borgaonkar, S. S. Wachtel, O. J. Miller, W. R. Breg, H. W. Jones, Jr., and J. M. Rary. 1977. Analysis of human Y-chromosome-specific reiterated DNA in chromosome variants. Proc. Natl. Acad. Sci. USA. 74:12451249.

35. Southern, E. M. 1975. Detection of specific sequences among DNA fragments separated by gel electrophoresis. J. Mol. Biol. 98:503-517.

36. Kozak, M. 1984. Compilation and analysis of sequences upstream from the translational start site in eukaryotic mRNAs. Nucleic Acids Res. 12:857-872.

37. Birnstiel, M. L., M. Busslinger, and K. Strub. 1985. Transcription termination and 3' processing: the end is in site! Cell. 41:349-359.

38. von Heijne, G. 1986. Mitochondrial targetting sequences may form amphiphilic helices. EMBO (Eur. Mol. Biol. Organ.) J. 5:13351342.

39. Roise, D., and G. Schatz. 1988. Mitochondrial Presequences. J. Biol. Chem. 263:4509-4511.

40. Koike, K., S. Ohta, Y. Urata, Y. Kagawa, and M. Koike. 1988. Cloning and sequencing of cDNAs encoding $\alpha$ and $\beta$ subunits of human pyruvate dehydrogenase. Proc. Natl. Acad. Sci. USA. 85:4145.

41. Danner, D. J., N. Armstrong, S. C. Heffelfinger, E. T. Sewell, J. H. Priest, and L. J. Elsas. 1985. Absence of branched chain acyltransferase as a cause of maple syrup urine disease. J. Clin. Invest. 75:858-860.

42. Litwer, S., W. J. Herring, and D. J. Danner. 1989. Reversion of the maple syrup urine disease phenotype of impaired branched chain $\alpha$-ketoacid dehydrogenase complex activity in fibroblasts from an affected child. J. Biol. Chem. 264:14597-14600.

43. Zhang, B., H. J. Edenberg, D. W. Crabb, and R. A. Harris. 1989. Evidence for both a regulatory mutation and a structural mutation in a family with maple syrup urine disease. J. Clin. Invest. 83:1425-1429. 